\title{
Improvement and efficiency: mass rapid transit station in Taipei
}

\author{
C.-N. Li \\ Department of Natural Resources, Chinese Culture University, Taiwan
}

\begin{abstract}
Taipei Mass Rapid Transit (MRT) system features a high level of efficiency, energy savings and high levels of cleanliness, thus being one of the most favoured networks among all transport modes in Taiwan. However, owing to high construction costs, the MRT normally needs attention paid to it in order to produce the expected benefits and levels of operating performance in the future, especially in the MRT station area where it matters the most. Therefore, the focus of the study targets the MRT station areas to establish three efficiency evaluation models - "passenger traffic/construction cost", "benefits of transportation environment/construction cost" and "benefits of passenger traffic and transportation environment/construction cost" through Data Envelopment Analysis (DEA) to evaluate the benefits of MRT station area and its operating efficiency. According to the outcome of an empirical study, Jiantan Station reports global technical efficiency and scale efficiency overall and has an optimal scale as per the "passenger traffic/construction cost" efficiency evaluation model. Muzha, Wanfang Hospital and Xinhai stations report optimal global technical and scale efficiency in terms of the "benefits of transportation environment/construction cost" efficiency evaluation model, while Muzha, Wanfang Hospital, Xinhai, Technology Building, Nanjing E. Rd., Shipai, Mingde and Jiantan stations report optimal global technical and scale efficiency in terms of the "benefits of passenger traffic and transportation environment/construction cost" efficiency evaluation model.

Keywords: design methods and aids, environment, rail and bus stations.
\end{abstract}

\section{Introduction}

In the past, the urban transportation systems in Taiwan were mainly highway systems, the common vehicles in use were mostly private motors and 
motorbikes, where many unsustainable situations existed in such transportation systems: e.g. emissions of mobile pollution would contribute to air pollution and also endanger the health of drivers and residents; greenhouse gas emissions would add to the greenhouse effect; petrochemical energy consumption was (and still is) compounding the shortages of non-renewable energy sources; an increase in private vehicle use has lead to more traffic congestion and is increasing time in transit and cost. Therefore, within a mindset of sustainable development, a private vehicle based highway system is inapplicable as the MRT that features high levels of efficiency, energy saving and cleanliness has become more favorable over time.

However, the performance of the MRT system will normally gather attention due to the associated elevated construction costs. Among the performances of a MRT system, decisions about the road network deployment and construction type matter the most, in which the location/position and number of stations are decisive in the deployment of the road networks, the operating performance of a MRT system will be enhanced if the location/position and the number of locations are well managed, or, will be reduced if not.

The methods emphasized in performance/efficiency analysis included the DEA, score card, ratio analysis, productivity measures and multiple regression analysis etc. $[1,2]$, in which the perspectives and applications that DEA cover are wider and therefore will be mostly adopted. Moreover, reviewing relative studies on the performances of MRT and mass transportation systems such as the studies [3-11] on the performance of MRT systems in the past focused mostly on road networks, revenue and operation methods and were less attentive to MRT station areas; also, the performance evaluation mostly started from the MRT itself, paying attention to the relationship between revenue and cost, and are mostly about analyses of collectable secondary data and were less attentive to the benefits of users, making the performance evaluation unable to accurately reveal all and become biased; besides, there has been no tangible or operable evaluation framework provided for reference concerning the efficiency evaluation of MRT station areas.

MRT station areas are a major part of transportation construction which not only affect the performance of the systems but also involves high investment costs, as well as there has yet not currently been a reasonable or objective evaluation framework and method, therefore, the paper targets these station areas to construct an objective, tangible and operable efficiency evaluation framework for related units to allow an efficient evaluation of station areas and provide suggestions for the improvement of inefficient MRT station areas; in addition, through an empirical study by the DEA, to expect the outcome of analysis to be regarded as references for the improvement and alteration of related units.

Due to its substantially high construction budget, however, the MRT system is always closely watched in terms of its performance. The most decisive factors of the performance perception are the road network deployment and the construction types, whilst the location/position and the number of stations play a crucial part in shaping the road network deployment. If the stations are well located/positioned and are of a realistic quantity, the MRT system will offer an 
acceptable level of operating performance, otherwise the performance can be impaired. There had been studies on the performance of MRT and public transportation systems in the past, such as studies [3-7, 12, 13], which were mostly focused on the lines of the MRT road network, as well as the revenue generated and operation of the MRT units, while the MRT stations were of less concern. Also, the performance assessment was mostly from the MRT unit's standpoint, focusing on the relationship between the revenue and cost that was analysed mainly with the secondary data that had been collected, while the user benefits were of notable less concern. As a result, the performance evaluation was not comprehensive and tended to be subjective. Additionally, the assessment of the MRT station performance lacked a specific assessment framework to operate within or make reference to.

The methods for performance or efficiency analysis have been carried out using the data envelopment analysis method (DEA), score card, ratio analysis, productivity measures, and multiple regression analysis [1,2], among which the DEA method is capable of handling evaluations on multiple inputs and outputs without the need of predefined production functions nor any given function parameters; plus, it can handle input and output elements of different measurement units without the need of given weighted values. Moreover, the DEA assessment can comprehensively represent the relationship between inputs and outputs, and the relative efficiency to other DMUs; it can also provide information for improvement by showing how much input should be reduced to inefficient units, or how many outputs should be added, in order to reach a suitable state of efficiency. Therefore, this study takes the DEA as the most appropriate analysis method.

To summarize, the MRT station, as a major form of transportation infrastructure, not only affects the performance of the MRT system itself, but also involves huge levels of investment. However, it has yet to have a reasonable and objective assessment framework and methodology. In view of this, this paper takes an insight into the MRT station, with an effort to construct an objective, specific and operational framework for the assessment of efficiency that can ultimately be used by all parties concerned to explore improvements for inefficient MRT stations. In addition, the MRT stations inside Taipei City are taken for empirical analysis, whose results hopefully can be used by competent authorities as references for the future alterations and developments of MRT stations.

The paper is divided into four parts, with research motives and purpose, contents and previous research outcomes stated as above, efficiency evaluation framework, evaluation indicator, variable and evaluation methods of the design of the MRT station areas stated in the second part, followed by empirical analysis on the efficiency of MRT station areas and the last part is conclusions. 


\section{Research design}

\subsection{The efficiency evaluation framework of MRT station areas}

The evaluation framework was drawn up by the study is shown as Figure 1. In addition to an analysis framework provided for the paper, it can be applied to the evaluation of MRT station areas in different regions and lines due to how the framework can be applied. The contents of various steps in this evaluation framework are as figure 1.

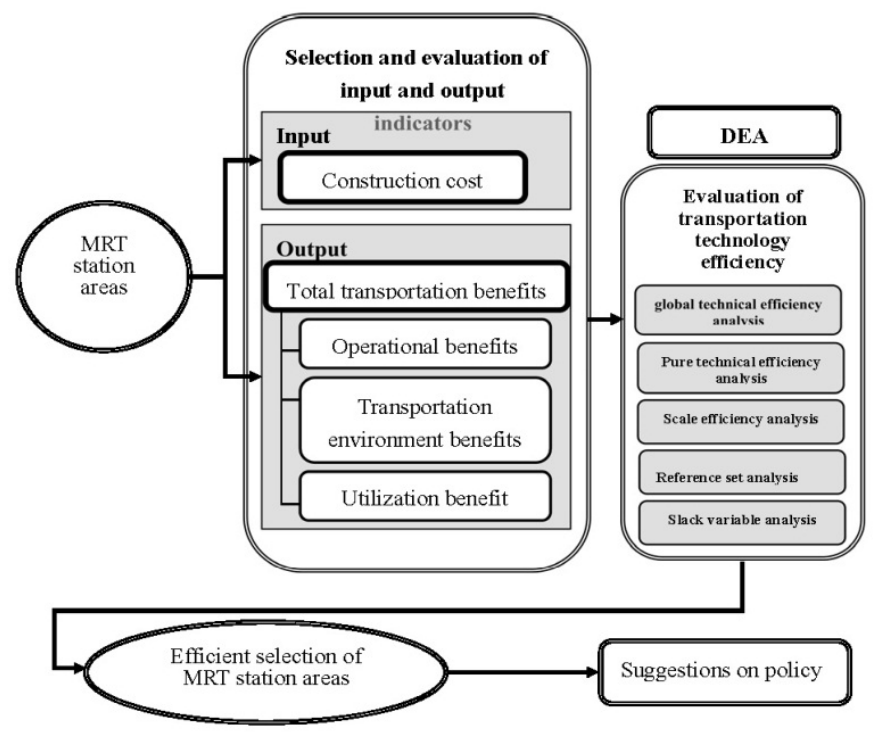

Figure 1: $\quad$ Research framework.

\subsection{Efficiency evaluation indicators of MRT station area}

Whatever the topic of efficiency evaluation may be, it is critical but difficult to choose representative input and output indicators during the evaluation process, while the costs and benefits of MRT stations involve intricate correlations and cross-influences and thus cannot be excluded. Consequently, to make an effective and comprehensive analysis of the MRT station's efficiency, this paper takes references to the studies [14-16], and under the limitation of data availability, 11 variables are selected for the efficiency measurement as the input and output indicators, and the variables' meanings, contents, codes and measurement units are summarized in Table 1. Of all the data, the MRT construction costs and passenger volumes are sourced from secondary data, and the rest has been acquired from survey data. 
Table 1: $\quad$ The list of measurement variables.

\begin{tabular}{|c|c|c|c|}
\hline Item & Measurement variable & Contents of variable & Unit \\
\hline Input & MRT construction cost & $\begin{array}{l}\text { Average construction cost of each } \\
\text { MRT station area }\end{array}$ & $\begin{array}{l}\text { tens of } \\
\text { millions }\end{array}$ \\
\hline \multirow{10}{*}{ Output } & Passenger volume & $\begin{array}{c}\text { Annual passenger volume of various } \\
\text { MRT station areas per year }\end{array}$ & $\begin{array}{l}\text { Tens of } \\
\text { thousands }\end{array}$ \\
\hline & $\begin{array}{l}\text { Number of } \\
\text { MRT uses }\end{array}$ & $\begin{array}{c}\text { How many times you use MRT as a } \\
\text { vehicle per week? }\end{array}$ & time/week \\
\hline & Distance to MRT station & $\begin{array}{l}\text { Do you think the distance to MRT is } \\
\text { far from where you start? }\end{array}$ & $\begin{array}{l}\text { Scale score } \\
\quad(0-10)\end{array}$ \\
\hline & $\begin{array}{l}\text { Linkage to sidewalk } \\
\text { around MRT station }\end{array}$ & $\begin{array}{c}\text { How do you feel like level of linkage } \\
\text { to sidewalk around MRT? }\end{array}$ & $\begin{array}{l}\text { Scale score } \\
(0-10)\end{array}$ \\
\hline & $\begin{array}{l}\text { Accessibility to the } \\
\text { sidewalk system around } \\
\text { MRT station }\end{array}$ & $\begin{array}{c}\text { How do you feel like level of } \\
\text { accessibility to the sidewalk system } \\
\text { around MRT? }\end{array}$ & $\begin{array}{l}\text { Scale score } \\
\quad(0-10)\end{array}$ \\
\hline & $\begin{array}{l}\text { Aesthetics of streets } \\
\text { around MRT station }\end{array}$ & $\begin{array}{c}\text { How do you feel like aesthetics of } \\
\text { streets around MRT? }\end{array}$ & $\begin{array}{l}\text { Scale score } \\
(0-10)\end{array}$ \\
\hline & $\begin{array}{l}\text { Comfort for the streets } \\
\text { around MRT station }\end{array}$ & $\begin{array}{c}\text { Howe do you feel like level of } \\
\text { comfort for the streets around MRT? }\end{array}$ & $\begin{array}{l}\text { Scale score } \\
(0-10)\end{array}$ \\
\hline & $\begin{array}{c}\text { Improvement in } \\
\text { congestion }\end{array}$ & $\begin{array}{l}\text { How do you feel like level of } \\
\text { improvement in traffic jam here after } \\
\text { the MRT is established? }\end{array}$ & $\begin{array}{l}\text { Scale score } \\
(0-10)\end{array}$ \\
\hline & Saving of travel time & $\begin{array}{c}\text { How do you feel like saving of travel } \\
\text { time you spent on your daily } \\
\text { activities? }\end{array}$ & $\begin{array}{l}\text { Scale score } \\
\quad(0-10)\end{array}$ \\
\hline & $\begin{array}{c}\text { Convenience of traffic } \\
\text { transfer }\end{array}$ & $\begin{array}{c}\text { How do you feel like level of } \\
\text { convenience of traffic transfer after } \\
\text { the MRT is established? }\end{array}$ & $\begin{array}{l}\text { Scale score } \\
\quad(0-10)\end{array}$ \\
\hline
\end{tabular}

\subsubsection{Input indicators}

The input item of "construction cost indicator" stands for the input cost and resources of the MRT station, whose measurement variable is based on the "MRT construction cost" that points to the real expenses on the construction of the individual MRT station. Since the cost of Taipei MRT is calculated by its routes rather than its stations, (1) shows the MRT station's construction cost calculated with the weighted values of the route and station cost. Equation (2) shows the MRT station's cost weight derived from the averaged weights of the station's site area, number of floors and entrances/exits, and station type. Equation (3) shows the weight ratio of a certain station's site area to the total area of all stations. Equation (4) shows the weight ratio of a certain station's number of floors to the total floors of all stations. Equation (5) shows the weight ratio of a certain station's number of entrances/exits to the total entrances/exits of all stations. Equation (6) shows the weight ratio of a certain station's type to the total weight of all station types.

$$
B C S_{i}=B C L_{m} \times W_{i}
$$




$$
\begin{gathered}
W_{i}=\left(\text { AREAP }_{i}+\text { TFP }_{i}+I O P_{i}+\text { TYPEP }_{i}\right) / 4 \\
A R E A P_{i}=\text { AREA }_{i} / \sum A R E A_{i} \\
T F P_{i}=T F_{i} / \sum T F_{i} \\
I O P_{i}=I O_{i} / \sum I O_{i} \\
T Y P E P_{i}=T Y P E_{i} / \sum T Y P E_{i}
\end{gathered}
$$

$B C S_{i}$ : Construction cost of MRT station area;

$B C L_{m}$ : Construction cost of MRT line;

$W_{i}$ : Cost weight of MRT station area;

$A R E A P_{i}:$ Weighted ratio of site areas of MRT station area;

$A R E A_{i}:$ Site areas of MRT station area;

$T F P_{i}$ : Weighted ratio of total floor numbers of MRT station area;

$T F_{i}$ : Total floor numbers of MRT station area;

$I O P_{i}$ : Weighted ratio of number of entry and exit of MRT station area;

$I O_{i}$ : Number of entry and exit of MRT station area;

$T_{T Y P P_{i}}$ : Weighted ratio of type of MRT station area;

$T Y P E_{i}$ : Weight of type of MRT station area;

i: MRT station area;

$\mathrm{m}$ : MRT line.

\subsubsection{Output indicators}

The total benefit of the MRT stations is referred to as the "total transport benefit" which includes "operational benefit", "transport environmental benefit" and "utilization benefit". Empirically, this study places the efficiency analyses of the individual station's construction cost against the "total transport benefit", as well as against the "operational benefit", "transport environmental benefit" and "utilization benefit", respectively. The meaning and measurement variables of the aforementioned benefits are described as follows:

\subsection{Efficiency evaluation methods of MRT station area}

\subsubsection{The decision making units (DMU) of efficiency evaluation}

DEA is to evaluate the relative efficiency of an object. Since different combinations of DMUs will affect the evaluation outcomes, homogeneity is usually considered in the selection of DMUs (Sun [1]; Bao [2]). Due to the similar developments of Taipei City and New Taipei City that have caused the two cities to develop MRT stations with similar patterns and objectives, it is 
important to select MRT stations within Taipei City that meet the homogeneity requirement. After filtering out the stations with inadequate amounts of information and a low level of questionnaire completion, there are 53 Taipei MRT stations with valid samples as DMUs.

\subsubsection{Efficiency evaluation model}

DEA has developed many corresponding models from different situations, however, the common aspect between these models are the guidance issues, i.e. most of the DEA models can be divided into input-oriented and output-oriented models, in which the purpose of the former is to derive the minimum possible proper input volume under current production while the latter model is to derive the maximum possible output volume under the current input. In this study, output orientation is introduced to calculate the DEA models such as CCR, BCC and FDH used for input analysis as the input cost is fixed, which applies to the maximum possible output under a fixed input number.

\subsubsection{Analysis of efficiency value}

The study proceeds with the evaluation of the relative efficiency of the MRT station area through an efficiency analysis of the DEA; moreover, to propose suggestions for improvement of relatively ineffective or inefficient MRT station areas, below are descriptions about the contents of the "efficiency analysis" and the analysis of "efficiency improvement".

\section{Empirical analysis}

\subsection{Description of sample data}

\subsubsection{Research area and space scope}

The Taipei Metro Mass Rapid Transit System (referred to as Taipei MRT) was this country's first such system to be built and brought into operation. It is also currently the largest MRT network in Taiwan. It is designed to ease the longstanding problems of traffic congestion within the Taipei metropolitan area. Commencing in 1988, and as of 2009, the MRT system has already had six routes within its operations, which are the Wenshan-Neihu, Danshui, Xindian, Gionher, Shiaonanman, and Bannan lines, with a total of 80 stations, whose services cover Taipei City and New Taipei City. The Taipei MRT has now become the transport backbone of the city's metropolitan area.

In consideration of the research purposes, the assumption of DMUs homogeneity, and the limited availability of secondary data, this study takes Taipei City as the domain to analyze the stations and routes that fall under its operations, which are the Wenshan-Neihu, Danshui, Xindian, Shiaonanman, Nangang and Banqiao lines. However, some of the stations are disregarded because of very little or even no survey data. As a result, only 53 stations are appropriate for the analysis (as shown in the DMU column of Table 2), and are taken as the DMUs.。 
Table 2: $\quad$ Efficiency evaluation outcomes upon total transportation benefits.

\begin{tabular}{|c|c|c|c|c|c|c|c|}
\hline & DMU & TTE & Rank & PTE & SE & RTS & Times being referenced \\
\hline 1 & Muzha Station & 1.00 & 1 & 1.00 & 1.00 & CRS & 18 \\
\hline 2 & Wanfang Hospital Station & 1.00 & 1 & 1.00 & 1.00 & CRS & 18 \\
\hline 3 & XinHai Station & 1.00 & 1 & 1.00 & 1.00 & CRS & 22 \\
\hline 4 & Technology Building Station & 1.00 & 1 & 1.00 & 1.00 & CRS & 5 \\
\hline 5 & Nanjing E. Rd. Station & 1.00 & 1 & 1.00 & 1.00 & CRS & 34 \\
\hline 6 & Shipai Station & 1.00 & 1 & 1.00 & 1.00 & CRS & 5 \\
\hline 7 & Mingde Station & 1.00 & 1 & 1.00 & 1.00 & CRS & 10 \\
\hline 8 & Jiantan Station & 1.00 & 1 & 1.00 & 1.00 & CRS & 22 \\
\hline 9 & Liuzhangli Station & 0.98 & 9 & 1.00 & 0.98 & DRS & - \\
\hline 10 & Shilin Station & 0.96 & 10 & 1.00 & 0.96 & DRS & - \\
\hline 11 & $\begin{array}{l}\text { Zhongshan Junior } \\
\text { High School Station }\end{array}$ & 0.94 & 11 & 0.99 & 0.95 & DRS & - \\
\hline 12 & Daan Station & 0.91 & 12 & 1.00 & 0.91 & DRS & - \\
\hline 13 & Xinbeitou Station & 0.90 & 13 & 1.00 & 0.90 & DRS & - \\
\hline 14 & Yuanshan Station & 0.89 & 14 & 0.99 & 0.90 & DRS & - \\
\hline 15 & Qiyan Station & 0.88 & 15 & 0.97 & 0.91 & DRS & - \\
\hline 16 & Zhishan Station & 0.87 & 16 & 1.00 & 0.87 & DRS & - \\
\hline 17 & Taipei Zoo Station & 0.86 & 17 & 1.00 & 0.86 & DRS & - \\
\hline 18 & Beitou Station & 0.86 & 18 & 0.98 & 0.87 & DRS & - \\
\hline 19 & Zongyi Station & 0.85 & 19 & 1.00 & 0.85 & DRS & - \\
\hline 20 & Linguang Station & 0.82 & 20 & 1.00 & 0.82 & DRS & - \\
\hline 21 & Fuxinggang Station & 0.78 & 21 & 1.00 & 0.78 & DRS & - \\
\hline 22 & Guandu Station & 0.77 & 22 & 1.00 & 0.77 & DRS & - \\
\hline 23 & Taipei City Hall Station & 0.71 & 23 & 1.00 & 0.71 & DRS & - \\
\hline 24 & Taipei Station & 0.67 & 24 & 1.00 & 0.67 & DRS & - \\
\hline 25 & Shuanglian Station & 0.62 & 25 & 1.00 & 0.62 & DRS & - \\
\hline 26 & Minquan W. Rd. Station & 0.55 & 26 & 0.93 & 0.59 & DRS & - \\
\hline 27 & Zhongshan Station & 0.54 & 27 & 1.00 & 0.54 & DRS & - \\
\hline 28 & Gongguan Station & 0.53 & 28 & 0.98 & 0.54 & DRS & - \\
\hline 29 & Ximen Station & 0.53 & 29 & 0.97 & 0.55 & DRS & - \\
\hline 30 & NTUH Hospital Station & 0.52 & 30 & 1.00 & 0.52 & DRS & - \\
\hline 31 & $\begin{array}{c}\text { Sun Yat-Sen } \\
\text { Memorial Hall Station } \\
\end{array}$ & 0.49 & 32 & 1.00 & 0.49 & DRS & - \\
\hline 32 & Longshan Temple Station & 0.49 & 31 & 0.98 & 0.50 & DRS & - \\
\hline 33 & Neihu Station & 0.47 & 33 & 1.00 & 0.47 & DRS & - \\
\hline 34 & Jingmei Station & 0.47 & 35 & 1.00 & 0.47 & DRS & - \\
\hline 35 & Zhongxiao Dunhua Station & 0.47 & 34 & 1.00 & 0.47 & DRS & - \\
\hline 36 & Neihu Park Station & 0.46 & 36 & 1.00 & 0.46 & DRS & - \\
\hline 37 & Yongchun Station & 0.46 & 37 & 0.99 & 0.46 & DRS & - \\
\hline 38 & Kunyang Station & 0.46 & 38 & 0.94 & 0.49 & DRS & - \\
\hline 39 & Gangqian Station & 0.44 & 39 & 0.98 & 0.45 & DRS & - \\
\hline 40 & Wende Station & 0.44 & 41 & 0.97 & 0.45 & DRS & - \\
\hline 41 & Shandao Temple Station & 0.44 & 42 & 0.97 & 0.45 & DRS & - \\
\hline 42 & Houshanpi Station & 0.44 & 40 & 0.93 & 0.48 & DRS & - \\
\hline 43 & Nangang Station & 0.41 & 43 & 0.94 & 0.44 & DRS & - \\
\hline 44 & Jiantan Station & 0.39 & 44 & 0.99 & 0.40 & DRS & - \\
\hline 45 & Taipower Building Station & 0.38 & 45 & 0.98 & 0.39 & DRS & - \\
\hline 46 & Zhongxiao Xinsheng Station & 0.37 & 47 & 0.90 & 0.40 & DRS & - \\
\hline 47 & Wanglong Station & 0.37 & 46 & 0.88 & 0.42 & DRS & - \\
\hline 48 & Xihu Station & 0.36 & 48 & 0.91 & 0.40 & DRS & - \\
\hline 49 & Guting Station & 0.35 & 49 & 0.96 & 0.37 & DRS & - \\
\hline 50 & Zhongxiao Fuxing Station & 0.35 & 50 & 0.91 & 0.38 & DRS & - \\
\hline 51 & Xiaonanmen Station & 0.33 & 51 & 0.99 & 0.34 & DRS & - \\
\hline 52 & $\begin{array}{c}\text { Chiang Kai-Shek } \\
\text { Memorial Hall Station }\end{array}$ & 0.28 & 52 & 1.00 & 0.28 & DRS & - \\
\hline 53 & Dazhi Station & 0.25 & 53 & 0.82 & 0.31 & DRS & - \\
\hline
\end{tabular}




\subsubsection{Descriptions of data}

Except for the MRT construction cost and secondary passenger volume collected data, the rest has been acquired from questionnaires, in which the calculation of variable data with regard to "MRT construction cost" such as the MRT line expenses and site areas, floor numbers, number of entry and exit points and various station types are mostly from studies and data provided by same Taipei department [17-22], while the variable data of the output item "passenger volume" is taken from data of the 2010 Statistical Yearbook of Transportation, Taipei City Department of Transportation, while variable data of other output items is taken from questionnaire data between May and July, 2010 conducted by random interview. As for data type, all variables are numbers, with "tens of millions", "tens of thousands" and "time/week" used as units to represent the "MRT construction cost", "passenger volume" and "number of MRT uses", the rest of variable data is all scaled.

\subsection{Empirical analysis}

The analysis outcome of the FDH model is not included as it did not report differences from the empirical analysis, below are descriptions and discussions in terms of the outcomes of efficiency, reference set and slack variable analyses.

According to the outcome of the DEA for total transportation benefit (Table 3), Muzha, Wanfang Hospital, XinHai, Technology Building, Nanjing E. Rd., Shipai, Mingde, and Jiantan stations report an efficiency value of 1 in terms of total technical efficiency, which are the MRT station areas which demonstrate relatively more efficiency, and at the same time, report pure technical and scale efficiency. However, among those MRT station areas that are relatively inefficient in terms of total technical efficiency if the level of those which report pure technical efficiency (Liuzhangli, Shilin, Daan, Xinbeitou, Zhishan, Taipei Zoo, Zongyi, LinGuang, Fuxinggang, Guandu, Taipei City Hall, Shuanglian, Zhongshan, NTU Hospital, Sun Yat-sen Memorial Hall, Neihu, Jingmei, Zhongxiao Dunhua, Dahu Park, and Chiang Kai-Shek Memorial Hall stations) is resultant from scale inefficiency instead of technology inefficiency. Moreover, as far as returns to scale are concerned, Muzha, Wanfang Hospital, XinHai, Technology Building, Nanjing E. Rd., Shipai, Mingde, and Jiantan stations represent optimal scales; while the remaining MRTs report a status of decreasing returns of scale, meaning that scale should be properly reduced to decrease the input volume so as to enhance overall efficiency.

If the analysis outcomes of operational benefit, transportation environment benefit and total transportation benefit are reviewed respectively, Wanfang Hospital and Jiantan stations simultaneously report total technical, pure technical and scale efficiency, meaning that they are more effective in terms of "passenger volume" and "number of MRT uses"; As far as returns of scale are concerned, Wanfang Hospital and Jiantan stations attain constant returns, meaning that they have an optimal level. Whereas Nanjing E. Rd., Muzha, and XinHai stations report a status of increasing returns of scale, meaning that a moderate expansion of scale is required to increase input volume to enhance overall efficiency, while the rest of stations areas all report decreasing returns of scale. 
Muzha, Nanjing E. Rd., and XinHai stations all report total technical, pure technical and scale efficiency at the same time in terms of transportation environment benefit, meaning that these areas are more efficient in terms of benefits generated from the neighborhood; as far as returns of scale are concerned, except for the aforementioned stations with a relative level of efficiency at an optimal scale, the rest of the MRT station areas all report a status of decreasing returns to scale.

Muzha and XinHai stations both report total technical, pure technical and scale efficiency at the same time in terms of utilization benefit, meaning that they are more efficient in terms of "saving of travel time" and "convenience of traffic transfer"; as far as returns to scale are concerned, except for the above mentioned MRT station areas with a relative level of efficiency located in an optimal scale, the rest of the MRT station areas all report a status of decreasing returns to scale.

As for the outcomes of different benefit analyses, it is known that the number and ratio of operation, transportation environment and utilization benefit all report less total transportation benefits in terms of the comparison between number and ratio of those which achieve the total technical efficiency level; as far as the allocation of total technical efficiency of all MRT station areas is concerned, total transportation benefits are centered from 0.4 to 0.69 , while transportation environment and utilization benefit are centered on two ranges; 0.7 to 0.99 and 0 to 0.39 while operational benefit reports a status of power law distribution. In addition, as far as pure technical efficiency is concerned, MRT station areas comprise a higher ratio in terms of total transportation benefit, meaning that MRT station areas that report no total technical efficiency in that model, in which there is a higher ratio, is resultant from scale inefficiency. Reviewing those inefficient MRT station areas upon other benefits, its higher ratio results from an inefficiency of scale and technology.

\section{Conclusions}

The study establishes an operable efficiency evaluation framework for MRT station areas, with MRT station areas in Taipei City used as objects to proceed with the empirical study in terms of the DEA approach and with research conclusions and suggestions proposed as below:

4.1 Targeting MRT station areas, the paper proposes a tangible and feasible efficiency evaluation framework which not only considers general operational benefit, but also covers transportation environment, use and total transportation benefit in terms of the efficiency perspective, allowing a more comprehensive and integrated analysis of the efficiency evaluation. Moreover, the evaluation framework is not only for related units to measure the efficiency of MRT station areas, but also provided as a direction and range of suggestions for the improvement of inefficient MRT station areas.

4.2 According to the outcome of empirical study in this paper, Muzha, Wanfang Hospital, XinHai, Technology Building, Nanjing E. Rd., Shipai, 
Mingde, and Jiantan stations are relatively efficient and achieve a level of optimal scale in terms of total transportation benefit for the time being. Nanjing E. Rd. Station reports the largest number of references by inefficient MRT station areas, therefore it reports the strongest steadiness in development efficiency while the number of references for Technology Building and Shipai stations are relatively less and hence report weaker steadiness in development efficiency.

\section{References}

[1] Sun, Xun (2004): (Data envelopment analysis: theories and applications". Taipei: Yang-Chih Book Co., Ltd. (In Chinese)

[2] Bo, Chiao-Ping (2005): "DEA of performance evaluation". Taipei: Wu-Nan Book Co. Ltd. (In Chinese)

[3] Benjamin, Julian and Kofi Obeng, (1990):The Effect of Policy and Backgroung Variables on Total Factor Productivity for Public Transit," Transportation Research B, 24(1): 1-14.

[4] Allen, W.G and Dicesare, F. (1976): "Transit Service Evaluation : Preliminary Identification of Variable Characterizing Level of Service”, TRR 746, TRB.

[5] Chu, X., and G. J. Fielding (1992):"Measuring Transit Performance Using Data Envelopment Analysis," Transportation Research, 26A(3): 223-230.

[6] Chang, Xue-Kong (1995): “A special report under the commission of Research, Development and Evaluation Commission, Executive Yuan, A study of performance and citizens' expectation of Taipei MRT system. (In Chinese)

[7] Chang, Xue-Kong, Chao, Chong-Ren, Lin, Gan-Chuan (2005): “A study of MRT system service level and its indicator", "Urban traffic", 20(2) : 27-42. (In Chinese)

[8] Dajani, J. and Gilbert, G. (1978): "Measuring the performance of transit systems", Transportation Planning and Technology, 4:97-103.

[9] Lan, Wu-Wang (1983): “(Part I) (Part II) A study of the evaluation of service level of mass transportation", "Transportation Planning Journal Quarterly", 22(2). (In Chinese)

[10] Litman, T. (2005): "Impacts of Rail Transit on the Performance of a Transportation System," Transportation Research Record: Journal of the Transportation Research Board, 1930:23-29.

[11] Lyons, D.M.(1995): Performance Measurement in Urban Transit: A Comparative Analysis of Single and Partial Measures of Transit Performance, AnnArbor, Michigan: UMI Company.

[12] Chang, Shu-Chun, Chang, Yuan-Kang, and Chang, Li-Hong(2010): “A Study on Service Satisfaction of Kaohsiung MRT", Journal of Architecture and Planning, 11(1) : 15-33. (In Chinese)

[13] Chen, Kan-Ti and Liu, Ming (2000): "MRT cost analysis and management", "MRT technologies", 23: 285-294. (In Chinese) 
[14] Fielding, G. J. (1992): "Transit Performance Evaluation in the U.S.A.," Transportation Research A, 26A(6): 483-491.

[15] Shi, Chung-Hao (1990) "Estimation of cost parameter of Taipei MRT system". Hsinchu: A dissertation of Institute of Traffic and Transportation, NCTU. (In Chinese)

[16] Tsai, Chi-Hung (2007): “A study of MRT Taipei system cost parameter and economic characteristics". Taipei: A dissertation of Department of Civil Engineering, NTU. (In Chinese)

[17] Department of Rapid Transit Systems, TCG (1998): “General report to the engineering of Muzha line for MRT Taipei”. Taipei: Department of Rapid Transit Systems, TCG. (In Chinese)

[18] Department of Rapid Transit Systems, TCG (2000): “General report to the construction of Chungho line, MRT Taipei”. Taipei: Department of Rapid Transit Systems, TCG.. (In Chinese)

[19] Department of Rapid Transit Systems, TCG (2003): "Mass Rapid Transit System in Taipei. Metropolitan Areas: general report to the construction of MRT Nangang Line". Taipei: Department of Rapid Transit Systems, TCG.. (In Chinese)

[20] Department of Rapid Transit Systems, TCG (2005): "General report to the construction of Hsintien line, MRT Taipei”. Taipei: Department of Rapid Transit Systems, TCG. (In Chinese)

[21] Department of Rapid Transit Systems, TCG (2006): "Planning and design practices of MRT station areas". Taipei: Department of Rapid Transit Systems, TCG.. (In Chinese)

[22] Taipei City Department of Transportation (2010): "Statistical Yearbook of Transportation, Taipei City". Taipei: Taipei City Department of Transportation. (In Chinese) 